\title{
Red de Escuelas de Empoderamiento de Bizkaia: una apuesta feminista arraigada en nuestros pueblos
}

\section{Maitane Picaza Gorrochategui}

Departamento de Didáctica y Organización Escolar, Facultad de Educación de Bilbao, UPV/EHU

maitane.picaza@ehu.eus

\section{Naiara Bilbao Quintana}

Departamento de Didáctica y Organización Escolar, Facultad de Educación de Bilbao, UPV/EHU

naiara.bilbao@ehu.eus

\section{Nahia Idoiaga Mondragon}

Departamento de Psicología Evolutiva y de la Educación, Facultad de Educación de Bilbao, UPV/EHU nahia.idoiaga@ehu.eus

Artikulu honen helburua Bizkaiko Ahalduntze Eskolen Sarea eta bere testuingurua aurkeztea da. Emakumeen ahalduntze ardatz duten eskola hauek Basauri, Ermua, Getxo eta Ondarroan daude kokaturik. Analisia burutzeko atzera begirako ikerketa gauzatuko dugu feminismo eta berdintasunaren mugarri dituen identitatearen eraikuntza aztertuaz udalerrien geografia eta historia abiapuntu gisa hartuta. Honela emakumeen udalerrietako proiektu sozialetan izandako protagonismo gakoa jorratuko dugu. Halaber, eskolek jorratutako hezkuntza ardatz nagusiak ere aztertuko dira ahalduntzearen bidez eskolek izandako helburu eta ardatzak ikertuaz.

\section{GAKO-HITZAK:}

Ahalduntzea, hezkuntza, feminismoa, sarea, emakumeak, udal zerbitzua.
Este artículo presenta la Red de Escuelas de Empoderamiento de Bizkaia, formada por cuatro escuelas sitas en los municipios de Basauri, Ermua, Getxo y Ondarroa. El objetivo de este artículo es enmarcar el contexto de la Red de Escuelas de Empoderamiento de Bizkaia. Para ello, realizamos una mirada retrospectiva que nos sitúa en una geografía de municipios y en una historia particular que marca la identidad de las escuelas en el presente en términos de feminismo e igualdad siendo las mujeres protagonistas y clave del proyecto municipal y social. Asimismo, se exponen las líneas formativas implementadas en las escuelas para facilitar el camino empoderante, presentando los objetivos y ejes principales de los centros.

\section{Palabras Clave:}

Empoderamiento, educación, feminismo, red, mujeres, servicios municipales. 
La Red de Escuelas de Empoderamiento (REE) de Bizkaia está formada por cuatro centros sitos en cuatro municipios: Basauri, Ermua, Getxo y Ondarroa. La red se consolida en el año 2004 y se crea para incentivar la reflexión que desemboca en reivindicación. Entender las escuelas requiere conocer la historia, lo que significa retrotraerse en el tiempo y en el espacio. Estas escuelas pueden considerarse versiones modernas de los grupos de autoconciencia vascos de los años setenta y ochenta, un movimiento feminista similar al británico centrado en la autoorganización local y la puesta en marcha de los servicios públicos (Esteban, 2014: 63). En este artículo se presenta esta red de escuelas, su historia y surgimiento, tanto de la red como en cada uno de los centros.

La elaboración de esta investigación se basa fundamentalmente en el análisis de contenidos de los textos escritos publicados en su mayoría por mujeres vinculadas a las escuelas, así como de sus webs oficiales. En particular, la publicación de Huellas feministas y de mujeres ${ }^{1}$ de Fernández (2014) ha sido guía importante y apoyo para elaborar la historia feminista de estas poblaciones. Asimismo, este artículo también incluye un análisis de los objetivos y los ejes de actuación de la red, así como de los datos de participación en las cuatro escuelas.

\section{Origen y evolución de la Red de Escuelas de Empoderamiento de Bizkaia}

El origen remoto de las escuelas como espacios donde las mujeres se reunían y participaban en actividades puede remitirse a los llamados Centros de Promoción de la Mujer que se crearon entre los años 1963 y 1964 en Bizkaia impulsados por la Caja de Ahorros Vizcaína, posteriormente BBK (Bilbao Bizkaia Kutxa) y actualmente Kutxabank (Fernández, 2015: 226). En un principio los centros nacieron a partir del entorno de la Iglesia para reforzar el papel tradicional de las mujeres a través de cursos de cocina o costura, entre otros.

\section{[...] acabaron convirtiéndose en espacios,} simbólicos y/o materiales de aprendizaje, de encuentro y de empoderamiento personal y colectivo para muchas mujeres, y se recupera por ellas como huella de asociacionismo, dando cuenta de cómo ciertos espacios creados con el propósito de consolidar roles de género tradicionales, pueden ser transformados en lugares desde los cuales se empiezan a cuestionar los patrones marcados, y conformándose así como lugares de educación y formación alternativa de mujeres adultas. Los centros acabaron convirtiéndose por estas mujeres en espacios de subversión y de cuestionamiento de los roles de género establecidos a finales de los años 70. (Fernández, 2015: 226)

${ }^{1}$ Los libros titulados Mapa de las Huellas de las Mujeres (Basauri, Ermua y Ondarroa) han sido escritos por Zaida Fernández Pérez, implementadora de la Casa de la Mujer de Ermua.
Estos centros eran espacios para mujeres; sin embargo, no albergaban explícitamente una iniciativa que predispusiera a las mujeres a evolucionar en sentido feminista. La génesis de la propuesta del proyecto de las escuelas de empoderamiento como espacio de participación sociopolítica se inspiró en prácticas de otros países, evolucionando los talleres existentes en otros más acordes a las necesidades de las mujeres en Euskal Herria, descartando el ocio como única vía de desahogo de estas e introduciendo un elemento ausente en sus vidas: una visión feminista y transversal del mundo.

Junto a la influencia de las escuelas británicas, Vázquez (2009), en su artículo sobre las Escuelas de Empoderamiento indica otras experiencias de América Latina y África. Las técnicas de igualdad vascas concretamente se inspiraron en la organización llamada Las Dignas (El Salvador), ${ }^{2}$ una organización política y feminista que surge en el umbral de los Acuerdos de Paz de 1990. Muchas de las mujeres que componen la organización salvadoreña se vieron afectadas por el conflicto armado. Cuentan en su historia que han estado en constante revisión y transformación luchando por la autonomía ideológica y económica y su encuentro con el feminismo, fundamento de su autonomía. Su misión sigue siendo promover la autonomía y el empoderamiento de las mujeres urbanas y rurales de diferentes clases e identidades, animándolas a hacer rupturas individuales y colectivas. En la organización las áreas de acción son la participación política, la difusión del pensamiento feminista y la formación donde existe una escuela de debate feminista ${ }^{3}$, se dirige a la participación y a la formación. Las técnicas de igualdad de Bizkaia se inspiraron en esta asociación y moldearon los espacios existentes en los municipios vascos a imagen de ella; se plantearon un tipo de escuela convencidas de que era necesario algo más que los cursos que impartían en las aulas culturales (Vázquez, 2009).

Las primeras escuelas de empoderamiento en Euskadi se crearon en Bizkaia donde ya había grupos feministas con trayectorias consolidadas, convirtiéndose en un proyecto pionero a nivel estatal. Concretamente, el proyecto se inició en el municipio de Basauri en el año 2003 a iniciativa del Área de Igualdad, como resultado de reflexionar sobre la participación política de las mujeres y la necesidad de impulsarlas desde el movimiento de mujeres e instituciones públicas (IV Jornada Feminista, 2008; Baltar et al., 2007; Fernández, 2015; Urzelai, 2014).

${ }^{2}$ Para más información se puede consultar la web de Las Dignas (Asociación de Mujeres para la Dignidad y la Vida), presente en El Salvador desde 1990: http://www.lasdignas.org.sv/.

${ }^{3}$ Los ejes estratégicos son la violencia contra las mujeres, la división sexual del trabajo, los derechos sexuales y reproductivos y las instancias socializadoras del sexismo. Cuentan con un centro cultural, un centro de documentación y un observatorio de las políticas públicas, el lenguaje sexista, la publicidad sexista, la violencia y los derechos sexuales y reproductivos. 
Basauri propuso el proyecto e inició la Red de Bizkaia de Escuelas de Empoderamiento para Mujeres con la idea de apoyar el movimiento feminista. Los ayuntamientos de Ermua y Getxo se unieron y finalmente, un año más tarde, se incorporó el municipio de Ondarroa, conformándose en el año 2004 la Red de Escuelas de Empoderamiento para Mujeres.

Esta red se convirtió en referente en la Comunidad Autónoma Vasca y Navarra. Hubo otros municipios que quisieron sumarse, pero por diferentes motivos, como no cumplir el requisito de igualdad que marcaba la red, o por criterio de tamaño, como fue el caso de Bilbao, las técnicas decidieron mantenerse en cuatro centros (Baltar et al., 2007) ${ }^{4}$. Sin embargo, de una manera informal se fueron y se van constituyendo redes al emerger diferentes escuelas de empoderamiento con las que tienen contacto.

Las primeras escuelas de empoderamiento de Gipuzkoa tomaron como base la experiencia de Bizkaia (Baltar et al., 2007; Urzelai, 2014). Surgió Jabetze Eskola ("Escuela de Empoderamiento", en euskera) porque se detectó la necesidad de realizar trabajo en red entre los distintos municipios guipuzcoanos y porque se quiso reforzar la participación política social de las mujeres. En el año 2005, las técnicas de igualdad de los municipios de Arrasate, Donostia, Eibar, Hernani, Irún y Tolosa se reunieron y finalmente fueron los municipios de Arrasate, Eibar, Hernani e Irún los que decidieron activar el proyecto hasta que en el año 2007 se consolidó, uniéndose Azpeitia y la mancomunidad de Urola Garaia (Urzelai, 2014).

A día de hoy, Jabetze Eskola es más que un referente, no solo es el espacio donde las mujeres encuentran cursos que las capacitan y las hacen autosuficientes, sino que es el lugar donde se fraguan proyectos y se forma a mujeres desde un enfoque y posicionamiento político feminista y participativo (Urzelai, 2014: 30). Así, en toda la Comunidad Autónoma del País Vasco (CAPV), las escuelas de empoderamiento pueden considerarse una pieza que alberga en su interior la totalidad de los ámbitos del feminismo, un gran salón donde convergen y se comunican personas feministas que provienen de diferentes campos sociales.

Si bien las Escuelas de Empoderamiento se enmarcan en el ámbito institucional, han sido espacios demandados por las feministas de cada municipio, y en la mayoría de los casos, el personal que las dirigen (técnicas de igualdad) son militantes feministas. (Fernández, 2015: 232)

La proliferación de estos espacios es latente ya que en el año 2019, funcionan en toda Euskal Herria veintitrés escuelas de empoderamiento (casas de las mujeres) que cuentan con espacios físicos en ocho municipios con Casas de Mujeres, el resto no

${ }^{4}$ Coincide con el discurso de la entrevista realizada a la técnica de igualdad de Getxo, Idoia Eizmendi, en 2014. tiene lugar propio y dispensan sus actividades en distintos centros. Por orden alfabético: Abadiño, Arrasate, Azkoitia, Azpeitia, Balmaseda, Basauri, Berriz, Donostia, Durango, Eibar, Elorrio, Erandio, Ermua, Errenteria, Getxo, Hernani, Mancomunidad de Arratia, Mancomunidad de Urola-Garaia (Ezkio Itsaso, Legazpi, Urretxu, Zumarraga), Ondarroa, Pasaia, Sestao, Sopelana 5 , Tolosa, Vitoria-Gasteiz, Zarautz y Zumaia (Berdingune, 2019).

Como señalan las técnicas de igualdad y las implementadoras en las entrevistas realizadas, las escuelas de empoderamiento que han surgido en diferentes municipios se han llamado de forma diversa, escuelas de empoderamiento, escuelas de mujeres, casas de mujeres, casas de empoderamiento, cursos de empoderamiento, entre otros pero al final el modelo es el mismo ${ }^{6}$. En euskera también adoptan diversos nombres, pueden llamarse jabetze eskolak o ahalduntze eskolak, emakumeen etxeak, emakume txokoak, etc. El modelo radica en lograr espacios para las mujeres donde puedan desarrollar sus capacidades o identificar las escuelas como un espacio propio.

Puede generase confusión entre las Casas de las Mujeres y las escuelas de empoderamiento. Las Casas de las Mujeres, o Emakumeen Topalekua, se crean por primera vez en Euskal Herria en el año 2003 en los municipios de Ermua y luego de Arrasate haciendo operativos espacios abiertos para "ofrecer información y formación, generar redes de empoderamiento y promover valores de igualdad visibilizarían y libertad, así como participar en actividades organizadas" (Fernández, 2015: 232). En líneas generales se puede decir que las casas son espacios municipales para mujeres y hombres con el fin de lograr la igualdad.

En estos hogares/espacios se agrupan diversos servicios para combatir las desigualdades y atender a las necesidades prácticas e intereses estratégicos de las mujeres y de la sociedad en su conjunto, por ejemplo, bancos de tiempo, oficina de información sexual, exposiciones o centros de promoción de la mujer, etc. Insertas en las Casas de las Mujeres, las escuelas de empoderamiento ocupan "habitaciones" importantes de la casa en sentido literal y figurado, ya que se piensan para lograr el empoderamiento de las mujeres. Además, estos espacios ofrecen servicio de guardería para las personas que ejercen de cuidadoras7, con el objetivo de facilitar la conciliación y que las mujeres puedan acudir a los talleres y demás actividades dispuestos en las escuelas.

${ }^{5}$ Escuela de Empoderamiento de Mujeres de Sopela (Berdintasuan y Sopelako Udala). Esta escuela tiene la particularidad de que los cursos puntúan con créditos de libre elección de la Uiversidad del País Vasco. Los cursos se imparten los viernes cada quince días y el precio del curso completo es de 36 euros; 〈https://sopelarin.sopelana.net/TSKultura/menu.aspx>.

${ }^{6}$ Implementadora del municipio de Basauri y técnica de igualdad de Getxo.

7 En el año 2014, momento de realizar las entrevistas Etxelila (escuela de empoderamiento de Ondarroa) aún no ofrecía el servicio de guardería que incorpora más tarde. 
En algunos municipios las Casas de las Mujeres son anteriores a las escuelas de empoderamiento como en el caso de Ermua o Arrasate. Mientras que en otros casos ocurre lo contrario ${ }^{8}$; así, en Basauri, Getxo y Ondarroa primero se crean las escuelas de empoderamiento y luego las Casas de las Mujeres.

\section{Características de las cuatro escuelas de la red: Basauri, Ermua, Getxo y Ondarroa}

Los cuatro municipios de la Red de Escuelas de Empoderamiento de Bizkaia ostentan identidades diferentes que pueden proyectar la experiencia de forma objetiva, "Aun siendo municipios con características variadas entre sí, las cuatro técnicas de igualdad de los municipios (Basauri, Ermua, Getxo y Ondarroa) compartían el objetivo común de impulsar la participación socio-política de las mujeres" (Baltar et al., 2007: 129). Los antecedentes históricos que han marcado el camino para que germine la idea de una Red de Escuelas de Empoderamiento en los cuatro municipios contemplan un recorrido histórico, feminista y asociado a entidades municipales con características propias. Como explica Anabel Sanz del Pozo, técnica de igualdad de la escuela de empoderamiento de Basauri, en una entrevista que concede a Círculo Solidario (Martín, 2007).

Los ayuntamientos tienen situaciones y trayectorias muy diferentes, no es lo mismo Getxo donde no se había hecho nada anteriormente, que Ermua que tiene una trayectoria de participación del movimiento feminista muy importante [... $]^{9}$ (Martín, 2007: 2).

A continuación, se expone brevemente la historia y características de cada municipio presentados por orden alfabético. La razón de situar geográficamente e históricamente los territorios radica en la importancia del espacio, por una parte, ya que la ubicación marca la identidad de las personas tanto por las características geográficas (mar, montaña, extensión, etc.) como por los territorios colindantes y vecinos. Por otra parte, entender la historia es necesario para poder comprender las acciones y la vida actual; se podría contar la historia, e incluso la prehistoria, pero sería fruto de otro trabajo, en esta investigación nos conformamos con abarcar pinceladas del comienzo de la segunda ola feminista.

${ }^{8}$ Para más información sobre las Escuelas de Empoderamiento, se pueden consultar las siguientes páginas web: 〈http://berdintasuna.basauri.net/index.php/es/escuela-de-empoderamiento〉; 〈http://www.getxo.eus/DocsPublic/igualdad/castellano/Escuela_ info_general.pdf〉; 〈http://www.ondarroa.eu/es-ES/Servicios/Igualdad/Paginas/igualdad_empoderamientoMujeres.aspx〉; 〈http:// www.ermua.es/pags/igualdad/ca_escuela_empoderamiento_objetivos.asp)>.

9 Se trata de una entrevista que la ONG Circulo Solidario de Euskadi realiza a la técnica de igualdad del Ayuntamiento de Basauri Anabel San del Pozo en el año 2007.

\section{A. Basauri: Marienea, Casa de las Mujeres}

El municipio de Basauri cuenta con una extensión de 7,16 km2 y se sitúa en la comarca metropolitana formada por Bilbao y otros pueblos a ambos lados de la ría del Nervión, en el bajo valle de los ríos Nervión e Ibaizabal ${ }^{10}$. Actualmente el sector servicios destaca en Basauri debido especialmente a la implantación del Mercado Central de Bilbao (MercaBilbao). Sin embargo, Basauri se caracteriza por ser de carácter obrero y vinculado a la industria desde el siglo XIX. El proceso de industrialización en el municipio conlleva el aumento de la población, que despunta notoriamente a partir de los años cincuenta con la instalación de nuevas industrias, creciendo la población en un $80 \%$ pasando de tener de pocos miles de habitantes a 55.000 habitantes en 1978. A partir de 1984, la reconversión industrial es la causa de un lento disminuir de la población (Azcona, 2003). En relación con los colectivos feministas, se pueden recordar las palabras de Fernández (2011: 15) cuando afirma: "Podría decirse que la construcción y reconstrucción de la identidad feminista colectiva en Basauri se ha gestado a través de habitar espacios y tiempos específicos", idea que se puede extrapolar a las demás escuelas y casas. La socióloga Fernández (2011), explica cómo en Basauri las mujeres han estado presentes de modos diversos (patronas, obreras, sindicalistas, escarabilleras) ${ }^{11}$ en este municipio con amplia tradición asociativa, hecho que ha enriquecido la forma de participación activa de las mujeres. En los años setenta se extiende el movimiento feminista, lo que ofrece la posibilidad de participación de las mujeres en lo que ellas consideran su propio destino, y es en los años ochenta cuando proliferan asociaciones de mujeres diversas.

En 1976 se conforma la Asociación de Mujeres de Basauri (AMB) como la primera asociación con perspectiva feminista del municipio (Epelde et al., 2015; Zabala, 2008). La organización, que sirve como espacio de sociabilidad, de difusión de ideas y como escuela de participación, la forma un grupo formado mayoritariamente por jóvenes. Sin embargo, se echaba de menos que "una mujer de edad avanzada aportara al colectivo experiencia y formación" (Pérez, 2006: 403). La aparición de este colectivo coincide con uno de los procesos judiciales de mayor impacto social de la época. Se trata de uno de los hitos feministas clave en Basauri, que ocurre con el conocido juicio de las once mujeres de Basauri, en 1975-1985, en el cual las mujeres fueron juzgadas por abortar (López, 2011). Este suceso marca el movimiento feminista vasco, ya que los juicios

${ }^{10}$ Para más información, se puede consultar la página web «www. basauri.net〉.

${ }^{11}$ Se conoce como escarabilleras a las mujeres que se dedicaban, a principios del siglo XX, en las regiones de mayor pobreza económica de muchos lugares de España, a buscar y recoger restos de carbón que no había prendido en su totalidad y que desechaban los trenes a vapor en los cruces de vías, así como de los restos carbón que las empresas metalúrgicas de la época desechaban en las escombreras tras las labores de fundición https://es.wikipedia.org/wiki/Escarabillera. 
tuvieron una gran repercusión social y política, provocando movilizaciones masivas. La AMB acude a París a informar al movimiento feminista francés sobre lo que estaba ocurriendo en Bilbao y a pedir apoyo para la amnistía de las mujeres. El movimiento feminista, situado en la llamada "segunda ola", era muy activo, su forma de trabajar en red promovía la actividad a todos los niveles. Según López (2011), en 1982 el movimiento feminista consideró un logro la sentencia que concedió indultos y fue absolutoria. Lo más importante de la sentencia fue la aplicación del estado de necesidad al amparo de la Constitución, que consistía en realizar una lectura progresista dado el vacío legal existente en el tema del aborto y la aplicación de delito imposible a seis de las acusadas. La autora concluye explicando que a finales de los años setenta las leyes vigentes elaboradas en el periodo franquista no eran representativas de la sociedad; una de las abogadas ${ }^{12}$ defensora de las mujeres describe este periodo como “...esa España negra” (López, 2011: 38). En cualquier caso, los juicios consolidan el movimiento feminista vasco y español. En Basauri se recuerda este suceso por medio de una placa conmemorativa creada por el Área de Igualdad de Basauri, que supone visibilizar la historia de las mujeres y un medio, como dice la autora, de "que las nuevas generaciones sean conscientes de lo difícil que fue en el pasado conseguir los derechos de los que ahora disfrutan" (López, 2011: 86).

En Basauri nace primero la escuela de empoderamiento, cuyos antiguos locales hicieron la función de Casa de la Mujer. Fruto de la reivindicación del Área de Igualdad de municipio, de las asociaciones y del movimiento feminista, en el año 2012 se inaugura la actual escuela de empoderamiento, llamada Marienea. Esta es en realidad una casa para las mujeres, ya que aglutina además de la escuela de empoderamiento, el Área de Igualdad, la Oficina de Información Sexual o el Centro de Información a Mujeres, Batera Bikain o Equitruque, además de ser un espacio que acoge diferentes actividades de asociaciones, ONG, exposiciones, etc. Es un espacio amplio y nuevo distribuido en salas con nombres de mujeres ${ }^{13}$ que destacaron en su tiempo. Además, alberga una pequeña cocina para uso público que le aporta carácter de hogar. Para su construcción se visitaron experiencias similares, como la Casa de la Mujeres de Zaragoza.

El Área de Igualdad es el órgano principal del cual dependen los servicios y recursos ubicados en Marienea (nombre que recibe la casa y escuela). El Consejo de Igualdad del Ayuntamiento de Basauri, por su parte, se constituye en el año 2001. La existencia de este consejo sectorial está prevista en la Ley de Bases de Régimen Local y pretende

\footnotetext{
${ }^{12}$ Mertxe Agundez abogada de una de las acusadas.

${ }^{13}$ Los nombres de las habitaciones o salas son: Sala 01, sala 02, sala Dolores Ibárruri, Sala Pepita Núñez, Sala Elbira Zipitria, Sala Po-
} lixene Trabudua. ser el engranaje entre el movimiento de mujeres organizado y la institución. Está compuesto por las asociaciones de mujeres ${ }^{14}$ que existen en el municipio y presidido por el concejal o concejala delegada del Área de Igualdad.

En la página web de la escuela de empoderamiento de Basauri se explica que es necesaria la participación para que la voz de las mujeres esté presente en las políticas públicas, para conseguir una sociedad más justa y equitativa, y para fomentar la presencia de las mujeres en espacios de toma de decisiones. Se plantea como estrategia de participación la integración de las mujeres en las asociaciones de mujeres y feministas que ya existen o formando nuevas asociaciones, participando en el Consejo de Igualdad, acudiendo a las actividades organizadas por el Área de Igualdad, como los cursos en la escuela de empoderamiento y acudiendo a encuentros o manifestaciones para reivindicar derechos.

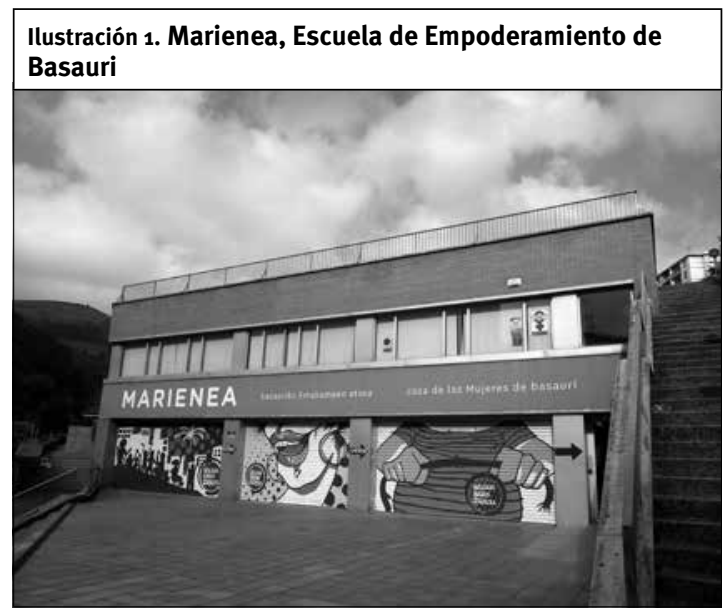

Fuente: Fotografía realizada por Maitane Picaza Gorrochategui.

\section{B. Ermua: Casa de la Mujer}

El municipio de Ermua cuenta con una extensión de $6,49 \mathrm{~km}^{2}$ y se sitúa en el extremo sudeste del territorio vizcaíno, formando parte del Duranguesado. Es la última población de la provincia de Bizkaia antes de entrar en Gipuzkoa (Área de Promoción Económica, Empleo y Formación, 2007). Se caracteriza por su carácter obrero y al igual que Basauri vivió un importante ascenso demográfico en la segunda mitad del siglo XX debido al movimiento migratorio proveniente de todas las regiones del Estado que acudía a trabajar en la industria de Eibar y Ermua; el sector económico principal continúa siendo la industria (Fernández, 2014). Los datos de Eustat muestran que en 1960 contaba con una

${ }^{14}$ Las organizaciones que componen el Consejo de Igualdad de Basauri son: Ate Zabalik, Manuela Egiguren: sociocultural amas de casa, Asociación de viudas, Asociación de Mujeres de Basauri, Grupo de Mujeres de EPA, Mujeres en la Diversidad, Mujeres de Aquí y de Allá, Zure Ondoan, Marienea Elkartea y Enproa. 
población de 3.020 personas y en una década llegó a la cifra de 14.651 habitantes.

Como apunta Fernández (2015), el municipio de Ermua destaca por contar con diferentes hitos feministas y luchar por la promoción de la igualdad de mujeres y hombres: en los años ochenta las mujeres reivindicaban recursos públicos para la puesta en marcha de servicios municipales de atención a mujeres víctimas de violencia de género. En 1987, el ayuntamiento puso en marcha una oficina de información para mujeres y un piso de acogida, el mismo año es el primer municipio de Euskadi donde se presentó la primera candidatura política de mujeres (1987). En esta candidatura las mujeres manifestaron la necesidad de un espacio propio para ellas, que demandaron también a través de la Asamblea de Mujeres de Ermua, y fueron presentadas en la III Jornada Feminista ${ }^{15}$ de Leioa en 1994.

En 1991 se creó el Departamento de Igualdad de Oportunidades de Mujeres y Hombres municipal con el objetivo del alcanzar la igualdad real; en 1992 se estableció la primera plaza de técnica de igualdad municipal. El Consejo de Igualdad, creado en 1991, es el primero en la Comunidad Autónoma Vasca, existe previamente a la Ley de Bases de Régimen Local y se considera el órgano de participación y espacio de interlocución entre el movimiento de mujeres y el ayuntamiento. En el consejo, además de participar con asociaciones y grupos de mujeres del municipio, se impulsan actividades de sensibilización y comparten buenas prácticas y experiencias con mujeres de diferentes partes del mundo. Continuando con los hitos de Ermua, se desarrolló el primer plan de igualdad municipal de mujeres y hombres (1995) con el que se creó un "piso refugio" para las mujeres, lo que será la antesala de la Casa de la Mujer que se construyó en marzo de 2003. Ermua contaba ya con la experiencia previa de los cursos formativos del Aula de la Mujer y otras experiencias impulsadas por la Asamblea de la Mujeres de Ermua, como Emakumeen Topalekua, donde se impartía formación y se compartían experiencias. El Aula de la Mujer surgió en los años noventa como espacio formativo y de participación para la puesta en marcha de procesos empoderantes. La Casa de la Mujer de Ermua (Ermuko Emakumeen Topalekua) es significativa por ser la pionera en Euskadi y anterior a las escuelas de empoderamiento que se integran dentro de la casa. La casa se percibe como un todo, donde además de la escuela de empoderamiento se realizan otras actividades. Por ejemplo, es el espacio donde se ha gestado la Plataforma de Cuidados de Bizkaia, lugar donde se reúnen las mujeres pertenecientes a la Asociación Profesional de Agentes de Igualdad (APAI) o del grupo de trabajo que ha realizado proposiciones sobre la Ley de Igualdad 4/2005 de la CAPV (Fernández, 2014; 2015). Esta casa es un edificio situado en el centro de Ermua, renovado por dentro y con tres plantas en las que se distribuyen salas, oficinas y hasta una cocina de uso público.

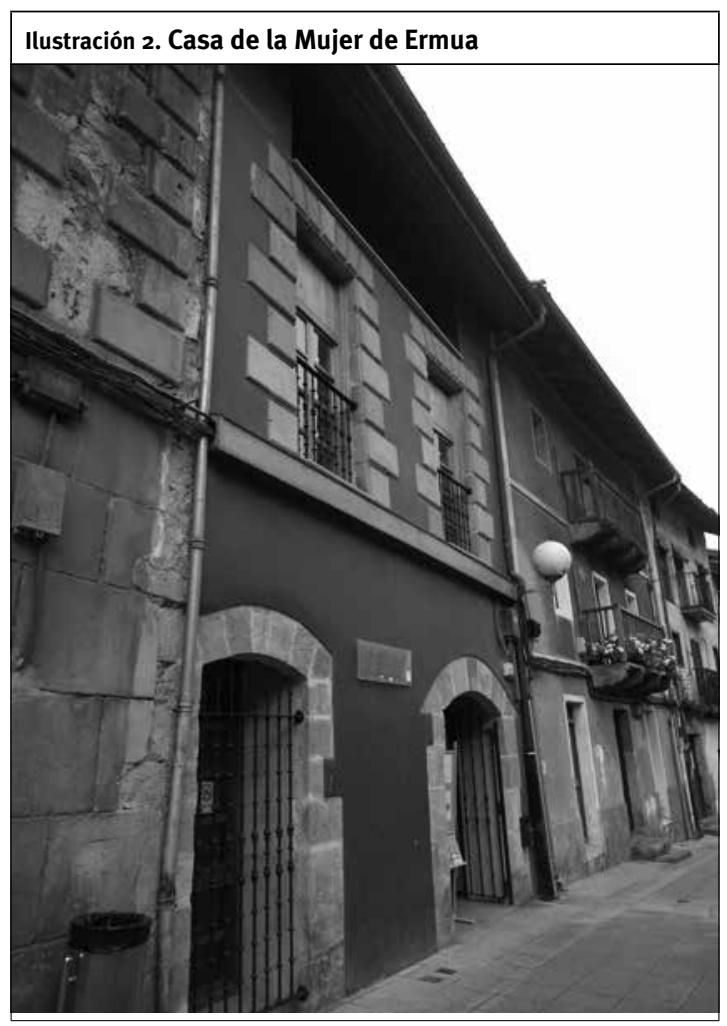

Fuente: Fotografía realizada por Maitane Picaza Gorrochategui.

\section{Getxo: Escuela de Empoderamiento de Getxo}

El municipio de Getxo cuenta con una extensión de 11,89 km2 y 79.544 habitantes en el año 2014; se sitúa en la margen derecha de la ría de Bilbao en la desembocadura del Ibaizabal-Nervión formando parte de la comarca del Gran Bilbao y destaca por los palacetes construidos por la alta burguesía en la industrialización. Sin embargo, el territorio de Getxo formado por barrios ${ }^{16}$ aglutina familias de diferentes clases socioeconómicas, considerándose Neguri un barrio burgués y Romo un barrio obrero.

Una primera característica de Getxo es que la documentación sobre historia e hitos feministas es más escasa que en el resto de los municipios de la red. Por este motivo, se ha preguntado a las técnicas de igualdad de las escuelas de empoderamiento sobre la falta de referencias de hitos feministas en Getxo, a lo que han respondido que la ausencia de documentación en este municipio también es un indicador sociocultural. El hecho de ser un municipio acaudalado ha podido frenar el impulso asociativoreivindicativo y público de las mujeres en el pasado. Sin embargo, las luchas de las mujeres en la historia también han sido privadas y anónimas y por ello

${ }^{15}$ Jornadas Feministas en Euskal Herria $(1977,1984,1994,2008)$, organizadas por colectivos feministas.

${ }^{16}$ Barrios de Getxo: Algorta, Las Arenas, Neguri, Romo, Santa María de Getxo. 
no menos valiosas. La escuela de empoderamiento de Getxo acoge otros cursos y programas ${ }^{17}$ además de los habituales que comparte con las otras tres escuelas en red y se caracteriza por el trabajo de apoyo a la población de mujeres inmigrantes, que en su mayoría trabajan como asistentas del hogar y cuidadoras en el municipio. La técnica de igualdad de la escuela de Getxo mantiene la oficina de Servicio de Igualdad en un edificio diferente a la escuela, ${ }^{18}$ lo que vive como una desventaja además de ser la única que no cuenta con la figura de implementadora. Estas dos circunstancias pueden dificultar la gestión diaria en las escuelas. Algunas de las actividades se desarrollan en la casa de cultura pública de Villamonte. Por eso, la reivindicación de unos locales propios es una constante. En la entrevista concedida a Circulo Solidario por la técnica de igualdad Sanz, esta afirma que "es fundamental el tema del espacio propio [...] Getxo está repartido en un montón de casas de cultura [...] estoy segura de que si tuviera un local propio [...] te permite otras cosas [...]" (Martín, 2007: 3).

\section{Ondarroa: Etxelila, Emakumin Jabekuntza Eskola}

El municipio de Ondarroa cuenta con una extensión de 3,6 km2 y 8.575 habitantes en el año 2014; se sitúa en la comarca de Lea-Artibai entre el mar Cantábrico, Berriatua, Amoroto, Mendexa y Mutriku (Gipuzkoa), y es la última población costera que forma parte de la provincia de Bizkaia antes de entrar en Gipuzkoa.

Ondarroa se caracteriza por dedicarse al sector industrial vinculado a la pesca, como fábricas de conserva o el remiendo de redes para la mar. Sin embargo, el sector servicios se ha desarrollado siendo hoy de importancia en el territorio. Es un municipio que ha vivido el fenómeno de la inmigración; en los últimos sesenta años, llegaron personas provenientes tanto de otras regiones del Estado como ciudadanos de Senegal que trabajan en la pesca. El condicionante de ser un pueblo de pescadores y que los hombres salgan a la mar ha impulsado que las mujeres ocupen espacios y que se hayan organizado, llegando a convertirse en base social y formando grupos de encuentro ${ }^{19}$, aunque fue después del franquismo cuando el movimiento feminista de Ondarroa se hizo más fuerte configurándose el primer grupo feminista, Ondarroako Emakumeen Taldea, en 1978. Este grupo se caracterizó por ser el primer grupo llamado "feminista". Al principio trabajaron la autoconciencia y comenzaron a darse a conocer fuera a pesar de

${ }_{17}$ Talleres para hombres, encuentros de mujeres migradas, diálogos interculturales entres mujeres, intervención en centros educativos.

${ }^{18}$ Servicio de Igualdad, calle Fueros n. 8; escuela de empoderamiento, calle Martikoena, 16.

19 Grupos: Herri Ekintza se crea en los años sesenta para tratar temas sociopolíticos; Herri Gaztedi desarrolla formación socio política; Jendarte Eskolak ofrecía formación sociopolítica a los emigrantes. Fuente: Fernández, (2012). combatir con las tradiciones de este pequeño pueblo (Fernández, 2012). A partir de este momento se fueron formando otros grupos como Boga-Boga, en el año 1995, y otros impulsados por la escuela de empoderamiento. Por ejemplo, la escuela organizó un taller dirigido por Graciela Atencio (“La República de las mujeres”, en 2004) que originó la preocupación por la inexistencia de un grupo feminista dedicado a la lucha contra la violencia a las mujeres en Lea-Artibai y así se creó UXU-Ondarroako Emakumeen Taldea (Arbelaitz et al., 2012).

Como muchas mujeres de pescadores, acostumbradas a asumir la gestión de la vida cotidiana, las mujeres de Ondarroa ostentan la fama de estar empoderadas. Sin embargo, a pesar de la dureza de enfrentarse a la organización familiar y social en soledad, la técnica de igualdad de Ondarroa opina que también necesitan empoderarse:

Desde fuera, sí se conoce la historia por encima y que los hombres salían a la mar, entonces las mujeres ondarrutarras han tenido que estar en el ámbito público, entonces según ese análisis si preguntas te dirán que las mujeres de Ondarru han terminado completamente el proceso empoderante tomando parte en el ámbito público, pero ya sabemos que en realidad ocurre lo mismo que en los demás pueblos ${ }^{20}$ (técnica de igualdad de Ondarroa, entrevista de 2014).

Ondarroa fue el último municipio en sumarse a la red de escuelas en el año 2004. En cuanto al edificio donde se ubica, la casa llamada Etxelila Emakumin Topaleku, se inaugura en el año 2013 como resultado de años de reivindicación de un espacio propio para las mujeres. Se trata de un edificio de dos plantas y la escuela se sitúa en la segunda, donde se distribuyen espacios donde se realizan los talleres, cursos y oficinas.

\section{Objetivos y ejes de actuación de la red de escuelas}

La Red de Escuelas de Empoderamiento de Bizkaia, como su propio nombre indica, abarca tres grandes apartados que se entretejen. Por una parte, se entiende la red como posibilidad de intercambio de experiencias, reflexiones y conocimiento, así como instrumento de fuerza. Por otra parte, el diseño del proyecto incide en los dos grandes conceptos de esta investigación, escuelas y empoderamiento, respectivamente.

La escuela se considera como vehículo de formación, ya que el proceso de aprendizaje es continuo

${ }_{20}$ "Kanpotik baten batek gainetik ezagutzen badu historia eta gizonezkoek kanpora joaten zirela orduan. emakume ondarrutarra bizitza publikoan egon behar izan da, orduan analisi horrekin eta gainera galdetzen baduzu baietz emakume ondarrutarra jabekuntza prozesua guztiz bukatuta dauka eta arlo publikoan parte hartzen du baina naiz jakin badakigu gertatzen dela beste herrietan bezela". 
a lo largo de la vida y condición para lograr el empoderamiento individual y colectivo. En este espacio de reflexión y aprendizaje mutuo, las mujeres se nutren en un intercambio de saberes y experiencias compartidas (Baltar et al., 2007; Fernández, 2015: 230).

Junto a "escuela", la segunda palabra clave es "empoderamiento" de las mujeres que subraya el proceso que va de lo individual a lo colectivo y de lo privado a lo público (Baltar et al., 2007).

Se fomenta el empoderamiento de las mujeres, entendiéndose este como el proceso de la toma de conciencia del poder que las mujeres tenemos tanto individual como colectivamente y que nos permite mejorar el acceso a todos los recursos, aumentar nuestra participación en la toma de decisiones, y por tanto, nuestra capacidad de influir (Fernández, 2015: 230).

Se trata de formar para la capacitación y la participación. Este proceso que va de lo individual a lo colectivo comienza con la toma de conciencia y el desarrollo de habilidades para analizar de forma crítica la situación en el mundo y así actuar en aras de la transformación política, social y cultural. Las escuelas son "para" el empoderamiento porque no empoderan, sino que facilitan las herramientas (Vázquez, 2009).

Vázquez (2009) resume los objetivos de las escuelas como cambiar la manera de pensar de las mujeres y trabajar una nueva conciencia del "nosotras". Las técnicas de igualdad en un artículo (Baltar et al., 2007), explican que, considerándose mujeres feministas y agentes para la igualdad, encuentran dos objetivos clave por su importancia estratégica; uno es la toma de conciencia de la desigualdad de las mujeres y otro es la participación sociopolítica activa de estas. Fernández (2015: 230), implementadora de la escuela de Ermua, explica que los objetivos principales de las escuelas son el empoderamiento a través de la formación, el ejercicio de la ciudadanía activa y la participación social y política de las mujeres.

En la primera página del informe de las escuelas de empoderamiento de la red de Bizkaia, escrito en clave institucional, se describe el objetivo general como "promover el empoderamiento de las mujeres de esta y de otras culturas a través de herramientas y procesos cuya sistematización fortalezca la participación sociopolítica de las mujeres" Este gran objetivo abarca diversas dimensiones y contenidos, y en él se hace referencia a los tres grandes ejes de intervención: el primero, trata de promover la participación sociopolítica de las mujeres de cada municipio de la red. El segundo, se centra en analizar y sistematizar el proceso para, en su caso, validar los instrumentos puestos en marcha.

${ }^{21}$ Consultar 〈http://www.getxo.eus/DocsPublic/igualdad/castellano/documentacion/objetivos_escuela.pdf〉.
El último, consiste en fomentar el conocimiento y la toma de conciencia colectiva sobre el sistema sexo-género y la situación de discriminación de las mujeres en el mundo. Para poner en práctica estos ejes de intervención se desarrollan diferentes líneas de formación donde las mujeres desarrollan capacidades.

Las técnicas de igualdad de las escuelas en red de Bizkaia alegan que los objetivos parten de una situación deficitaria debido a la desigualdad estructural del sistema sexo-género y añaden que las políticas de igualdad se han interpretado como actividades de entretenimiento en lugar de darles una visión empoderante. Las escuelas se crean para pasar de lo práctico a lo estratégico, atender primero las necesidades prácticas derivadas de un sistema condicionado por la cultura sexo-género, para evolucionar a un interés estratégico en el plano del empoderamiento, materializado por la participación en el espacio público y en el ejercicio de la ciudadanía activa (Baltar et al., 2007).

Las líneas y estrategias de las escuelas se enraízan en un entramado de atender las necesidades prácticas de las mujeres para desarrollar los intereses estratégicos en un momento posterior.

\section{Líneas de formación}

Las escuelas de empoderamiento desarrollan líneas de formación y a partir de estas se intenta llegar a los contenidos, que a su vez responden a los objetivos de las escuelas. Las líneas formativas ${ }^{22}$ se diseñan abarcando materias desde una perspectiva feminista; las cuatro escuelas han acordado cuáles son sus ejes de actuación y sus líneas formativas que se han registrado en la Tabla 1: feminismo, identidad y subjetividad femenina, salud, redefinición de la cultura, comunicación, solidaridad e intercambio de mujeres del mundo, reforzando la autonomía y participación política y social. Por otro lado, cada línea de formación engloba una serie de cursos y talleres que pueden repetirse a lo largo del tiempo o introducir nuevos, según las demandas y necesidades de las participantes. A continuación se explican las líneas de formación:

- Feminismo: trata temas vinculados a la teoría feminista.

- Identidad y subjetividad femenina: se refiere a aspectos psicológicos, como la gestión de emociones.

- Salud: trata temas relacionados con la sexualidad y el cuerpo, como la menopausia o el suelo pélvico, y también engloba talleres de cuidados, entre otros.

${ }^{22}$ Documento donde las cuatro escuelas acuerdan las líneas de actuación y líneas de formación: 〈http://www.getxo.eus/DocsPublic/ igualdad/castellano/Escuela_info_general.pdf〉. 
- Redefinición de la cultura: trata de talleres centrados en el arte de las mujeres; se estudian mujeres artistas y se interpreta el arte desde el punto de vista femenino.

- Comunicación: se centra en el arte de la oratoria, por eso se introducen talleres que impliquen el aprendizaje de habilidades para hablar en público.

- Solidaridad e intercambio de mujeres del mundo: desarrolla cursos donde integran temas globales de mujeres de otros países o mujeres inmigrantes.

- Reforzando la autonomía: incluye talleres prácticos vinculados culturalmente al rol masculino.

- Participación política y social: contiene talleres vinculados a la participación comunitaria.

A modo de ejemplo, en la Tabla 1 se han anotado algunos talleres según su línea de formación, elegidos entre los programas formativos de las cuatro escuelas entre los años 2010 y 2017. Las escuelas de empoderamiento se coordinan y trabajan en red, compartiendo las líneas de formación y los talleres. Son las escuelas de Basauri y Getxo las que experimentan con ciertos cursos y talleres a modo de laboratorio y en caso de funcionar los introducen en las escuelas de Ermua y Ondarroa.

Las figuras y roles de las mujeres que trabajan en las escuelas son las técnicas de igualdad, las implementadoras y las formadoras. Las primeras son funcionarias que dirigen las casas y escuelas como directoras o técnicas en la materia. Las implementadoras son trabajadoras con estudios superiores que desarrollan diferentes funciones como trabajo de implementación, documentación, coordinación y gestión, entre otros. Por último, las formadoras son las docentes que imparten y dirigen los talleres y cursos en las aulas.

Aunque todas las escuelas aplican las líneas formativas mencionadas, cada escuela posee autonomía para introducir los talleres que considere más apropiados para su contexto y que responden a la demanda de las mujeres. En el caso de Getxo, por ejemplo, se refuerza la línea de solidaridad e intercambio de mujeres en el mundo. Las líneas de formación contienen diversos talleres que funcionan año tras año en las cuatro escuelas; sin embargo, en el caso de la línea de participación política y social se han encontrado pocos talleres ofertados en los programas formativos. Por ejemplo, el taller "Liderazgo y trabajo en equipo" que se indica en la Tabla 1, se ha obtenido del programa de Getxo en el año 2010-2011 y no se ha vuelto a repetir en los últimos años.

Las líneas de formación se basan en ofrecer formatos de aprendizaje desde una óptica feminista. En la línea de feminismo, por ejemplo, se imparten talleres de literatura feminista por Skolastika, centro literario de crítica feminista que se crea en Bilbao en el año 2003-2004, donde se desarrollan talleres de mujeres escritoras del mundo (África, Asia, Europa, etc.). El objetivo es el empoderamiento y el desarrollo de la identidad de las mujeres, pero también dar a conocer las identidades de las mujeres creadoras y sus trabajos (Epelde et al., 2015: 576). También lo es visibilizar el trabajo que no se presenta en la enseñanza formal, al igual que otros talleres ligados al arte como los cursos de pintura y mujer donde se diserta sobre cuadros pintados por mujeres a lo largo de la historia.

Otro ejemplo de taller inserto en la misma línea es la autodefensa feminista que incentiva la autonomía. El método extendido en Estados Unidos y Europa se introduce en el movimiento feminista en Euskadi en la década de los ochenta. Se comprende que, para las mujeres puedan responder físicamente, primero se tiene que autorizar a actuar legitimándose en su capacidad. De este modo, se trabaja la confianza individual y colectiva (Epelde et al., 2015). Su objetivo es convertir a las mujeres en sujetos activos para que dejen de ser víctimas pasivas y lograr la ruptura de sus roles tradicionales, reivindicando su derecho a ocupar el espacio público (Emakunde, 2011: 43).

Tabla 1. Líneas de formación y talleres de las cuatro escuelas de empoderamiento en red

\begin{tabular}{|c|c|}
\hline $\begin{array}{l}\text { Líneas formativas } \\
\text { de las escuelas }\end{array}$ & Talleres (algunos ejemplos) \\
\hline Feminismo & $\begin{array}{l}\text { - Teoría sobre feminismo. } \\
\text { - Autodefensa feminista. } \\
\text { - Violencia simbólica. } \\
\text { - Urbanismo, género y participación } \\
\text { - Ecofeminismo. } \\
\text { - Ley integral contra la violencia de género. }\end{array}$ \\
\hline $\begin{array}{l}\text { Identidad y } \\
\text { subjetividad } \\
\text { femenina }\end{array}$ & $\begin{array}{l}\text { - Gestión de emociones. } \\
\text { - Aprender a quererse. } \\
\text { - "Desprincesamiento” y amor romántico. } \\
\text { - Hablar de duelo. }\end{array}$ \\
\hline Salud & $\begin{array}{l}\text { - Reforzando el suelo pélvico. } \\
\text { - Cuidar cuidándonos. } \\
\text { - ¿Qué sabes de tu cuerpo que tú no sabes? } \\
\text { - Sexualidad, menopausia. }\end{array}$ \\
\hline $\begin{array}{l}\text { Redefinición de la } \\
\text { cultura }\end{array}$ & $\begin{array}{l}\text { - Literatura feminista. } \\
\text { - Bertsolarismo. } \\
\text { - Cómic para mujeres. } \\
\text { - Arte y feminismo. } \\
\text { - Teatro y danza. } \\
\text { - Creatividad. }\end{array}$ \\
\hline Comunicación & $\begin{array}{l}\text { - Hablar en público. } \\
\text { - Activa tu voz }\end{array}$ \\
\hline $\begin{array}{l}\text { Solidaridad e } \\
\text { intercambio de } \\
\text { mujeres del mundo }\end{array}$ & $\begin{array}{l}\text { - Diálogo intercultural entre mujeres. } \\
\text { - Mujeres saharauis. } \\
\text { - Mutilaciones genitales femeninas. }\end{array}$ \\
\hline $\begin{array}{l}\text { Reforzando la } \\
\text { autonomía }\end{array}$ & $\begin{array}{l}\text { - Mecánica de bicis. } \\
\text { - Mecánica de coches. } \\
\text { - Carpintería. } \\
\text { - Electricidad. }\end{array}$ \\
\hline $\begin{array}{l}\text { Participación } \\
\text { política y social }\end{array}$ & - Liderazgo y trabajo en equipo \\
\hline
\end{tabular}

Fuente: Elaboración propia, basada en las páginas web de cada escuela de empoderamiento. 
Anabel Sanz (técnica de igualdad de Basauri), explica que los talleres y cursos de psicología en la línea de identidad y subjetividad femenina tienen mucho éxito; contratan psicólogas feministas que aclaran desde el primer día que no es un espacio para hacer terapia, sino para reflexionar sobre la situación de las mujeres (Martín, 2007).

La IV Jornada Feminista (2008) exponen las iniciativas formativas de estas escuelas de empoderamiento en torno a los "cuidados" que se engloban en la línea dirigida a la salud. Mencionan el Plan de Acción para el Cuidado en el Municipio de Ermua, los talleres participativos en los que intervienen más de cien personas, mayoritariamente mujeres, donde se elabora el Decálogo sobre Cuidados a Personas en situación de Dependencia en Getxo (2007) y el diagnóstico a petición del Consejo Municipal de Igualdad presentado en Ondarroa. Se explica cómo se pasa en los talleres de la queja a la reflexión y de la reflexión a la reivindicación, en un movimiento ciudadano liderado por mujeres.

El taller de bertsolarismo, inserto en la línea de redefinición de la cultura, se imparte desde una nueva visión en las escuelas. La primera mención que se hace sobre el bertsolarismo y las mujeres data d el siglo XV, en el Fuero Vizcaíno, que dicta una prohibición sobre mujeres ${ }^{23}$. Otra prohibición del mismo fuero en el año 1452 sobre los cantos y coplas públicas de las mujeres ${ }^{24}$, hace pensar que era habitual que las mujeres compusieran versos en duelos y celebraciones. Además, aunque se deslegitima a las mujeres para cantar en la plaza pública, estas siguen cantando en casa, lo que induce a pensar que la prohibición es expresión de que las mujeres eran protagonistas en la arena pública (Larrañaga, 2007: 60). Es muy significativo, ya que es un caso de desempoderamiento y se entiende que si se prohíbe a las mujeres cantar en público es porque han cantado en la calle. Larrañaga (2007: 63) afirma que las mujeres han contribuido a esta disciplina desde los hogares y una vez más la cultura y las normas sitúan a las mujeres en el espacio privado.

La falta de tradición y legitimación de las mujeres al hablar en el espacio público merma su disposición a hacerse oír cuando la capacidad se mutila socialmente. Los cursos de hablar en público en la línea de comunicación atraen a mujeres que no están acostumbradas a este tipo de comunicación, muy ligados a los cursos de psicología, en palabras de Sanz (Martín, 2007).

Las Katalinak se crean en el año 2010 para romper con el pensamiento machista del mundo de "la bicicleta", pretenden incentivar el ocio de la mujer introduciendo la óptica feminista. Además, la bicicleta como vehículo ha supuesto un cauce de independencia para muchas mujeres. Sin embargo, hoy en día se desconoce su manejo mecánico. En las escuelas detectaron que era necesario realizar talleres de mecánica de bicis y los impartieron. Este tipo de talleres corresponden a la línea "reforzando la autonomía”.

Además de la amplia gama de cursos y talleres, los horarios son muy variados. La combinación es heterogénea: pueden realizarse una vez a la semana o una vez al mes; entre semana a la tarde, alguno a la mañana, o de fin de semana; en tramos de un mes o de tres meses. La duración de los talleres puede ir desde una única sesión de dos horas hasta cincuenta horas divididas en varias sesiones, aunque la mayoría dura entre 8 y 14 horas repartidas en sesiones de dos horas.

Tabla 2. Registro de mujeres asistentes y talleres-cursos ofrecidos (2013-2014)

\begin{tabular}{|c|c|c|c|}
\hline Escuela & $\begin{array}{l}\text { Número de alumnas y de mujeres en el } \\
\text { municipio }\end{array}$ & Número de cursos ofrecidos & Número de cursos suspendidos \\
\hline Basauri & $\begin{array}{l}\text { - } 208 \text { alumnas (o,96 \%) } \\
\text { - } 21.555 \text { mujeres }\end{array}$ & 18 cursos & $\begin{array}{l}\text { Dos cursos suspendidos por falta de } \\
\text { participantes: } \\
\text { - Taller de teatro y literatura. } \\
\text { - Taller de clown para jóvenes. }\end{array}$ \\
\hline Ermua & $\begin{array}{l}\text { - } 139 \text { alumnas }(1,72 \%) \\
\text { - } 8.063 \text { mujeres }\end{array}$ & 12 cursos & $\begin{array}{l}\text { Se suspende un curso por falta de } \\
\text { participantes: } \\
\text { - Reconstruyendo historias con imágenes, } \\
\text { Beldur Barik. }\end{array}$ \\
\hline Getxo & $\begin{array}{l}-181 \text { alumnas (o,42 \%) } \\
\cdot 42.369 \text { mujeres }\end{array}$ & 15 cursos & - \\
\hline Ondarroa & $\begin{array}{l}\text { - } 149 \text { alumnas }(3,41 \%) \\
\text { - } 4.367 \text { mujeres }\end{array}$ & 11 cursos & - \\
\hline
\end{tabular}

Fuente: Elaboración propia a partir de los datos obtenidos por las técnicas de las escuelas y Eustat (2011).

23 "Sobre mujeres que son conocidas por desvergonzadas y revolvedoras de vecindades y cantares" (que el fuero llama "profazadas") (El Fuero, 1977).

24 Título 35, ley VI. 
Las implementadoras y técnicas de igualdad registran anualmente los datos relativos a la asistencia y formación: el número de mujeres apuntadas, el número de cursos y talleres ofertados y los cursos suspendidos (en caso de poca demanda). En la Tabla 2 se muestran estos datos correspondientes al curso 2013-2014. Estos datos han sido facilitados por las implementadoras y técnicas de igualdad de las cuatro escuelas. También se han recogido datos poblacionales de Eustat para el año 2011.

Las escuelas de Basauri y Getxo son los centros con mayor afluencia de mujeres, con 208 y 181 participantes, respectivamente. Ermua y Ondarroa, aunque algo menos, han recibido a 139 y 149 mujeres en sus cursos. Por otro lado, la mayor oferta formativa la ofrece la escuela de Basauri (18 cursos) luego Getxo (15 cursos), después Ermua (12 cursos) y finalmente Ondarroa (11 cursos). Sin embargo, si se toman en cuenta los datos de poblaciones y la situación geográfica de cada centro, no se cumple una proporción. Es decir, de las 595.586 mujeres empadronadas en Bizkaia, se ha distribuido el número de mujeres según municipio y se han comprobado los siguientes datos: Getxo es el municipio más poblado, sin embargo, el porcentaje proporcional de mujeres que asiste a la escuela es el más pequeño (0,42\%); le sigue Basauri (0,96\%). En cambio, en Ermua (1,72\%) y Ondarroa (3,41\%), el número de mujeres censadas es menor pero en proporción la participación de alumnas es mucho más alta comparando con Basauri y sobre todo con Getxo. Concretamente, Ondarroa es el municipio menos poblado y con mayor participación proporcional de mujeres, ya que de 4.367 mujeres acuden 149 alumnas.

Por último, cabe comentar el éxito que suele tener la oferta de las distintas escuelas. En el curso 20132014, Basauri ha tenido que suspender dos cursos y Ermua uno, las escuelas de Getxo y Ondarroa han impartido todos los cursos ofertados.

\section{Conclusiones}

Del análisis realizado se puede concluir que la Red de Escuelas de Empoderamiento está lejos de ser un lugar para pasar un "buen rato"; su objetivo es más ambicioso y sofisticado. Las técnicas de las cuatro escuelas en un artículo titulado "Ni ocio ni tiempo libre”, escriben desmarcándose de este objetivo.

[...] la intervención municipal se ha dirigido a la organización de actividades de ocio y tiempo libre de las mujeres, la Escuela de Empoderamiento no es -desde luego- el espacio para ello [...] en este proyecto que implica un proceso lento, no tanto de impacto, se establecen itinerarios para avanzar desde la capacitación hacia el compromiso (Baltar et al., 2007: 129).

Por lo tanto, este proyecto o servicio responde a una necesidad que las mujeres sienten: "ofrecimos cosas como participación social y política, técnicas de hablar en público, cosas de ese tipo. Y las mujeres acudieron en un número importante" y "estar en una especie de laboratorio" (Martín, 2007: 1). Planteando las escuelas como lugares de experimentación, el objetivo se centra en concienciar, pero desde la óptica feminista, lo cual es algo innovador y transgresor. Por tradición y cultura social, la educación se ha diseñado desde una historia que se imparte por hombres y para formar a hombres desde un prisma masculino. La educación germina en una llustración que habló de hombres y no de personas, se practicó así la exclusión de las mujeres en la educación consolidando un sistema educativo no inclusivo basado en la desigualdad social entre sexos. La nueva perspectiva feminista atrae a las mujeres que no han tenido la oportunidad en las distintas formaciones de aprender y desarrollarse y capacitarse en este sentido. Amartya Sen (2000) entiende la falta de oportunidad como una desigualdad que priva a la persona de una vida plena y libre y acentúa la inequidad de género. Además, añade que las mujeres tienen derecho a realizarse a sí mismas y a recibir una educación que les sirva como herramienta para alcanzar cotas de bienestar. Para todo ello la Red de Escuelas de Empoderamiento de Bizkaia constituye un servicio clave y por consiguiente merecen el reconocimiento que mediante este artículo se les ha querido otorgar ante la sociedad. 
ARBELAITZ, M.; ORMAZABAL, A., y RIVERAS, A. (2012): Ondarroako Emakumeak Herriko Partaidetza Politikoan eta Sozialean. Emakumeen asoziazionismoaren eta mugimendu feministaren bilakaera eta horien eragina Emakumeen boteretzean (1978-2006), Ondarroak, Berdintasun Saila.

AZCONA, J. M. (2003): Historia General de la Villa de Ermua, Ermua, Ayuntamiento de Ermua.

BALTAR, R.; SANZ, A.; FERNÁNDEZ, B. y EIZMENDI, I. (2007): "Ni ocio ni tiempo libre. Red de Escuelas de Empoderamiento para mujeres: Basauri, Ermua, Getxo y Ondarroa (Bizkaia)", ADOZ: Revista de estudios de ocio, 31, pp. 129-132.

BERDINGUNE (2019): Euskadi.eus, obtenido de 〈https://www. berdingune.euskadi.eus/u89-homeberd/es>.

EMAKUNDE. (2011): Estudio sobre las mujeres inmigrantes extranjeras de la sociedad vasca, VitoriaGasteiz, Emakunde.

EPELDE, E.; ARANGUREN, M. y RETOLAZA, I. (2015): Gure genealogiak feministak Euskal Herriko Mugimendu Feministaren kronika bat, Gipuzkoa, Emagin Dokumentazio eta Ikerkuntza Zentro Feminista.

ESTEBAN, M.L. (2014): "El feminismo vasco y los circuitos del conocimiento, la universidad y la casa de las mujeres". En MENDIA, I.; LUXAN, M.; LEGARRETA, M.; GUZMÁN, G.; ZIRION, I. y AZPIAZAU, C.: Otras formas de (re)conocer. Reflexiones, herramientas y aplicaciones desde la investigación feminista, País Vasco, Hegoa, EHU.

FERNÁNDEZ, Z. (2011): Mapa de las Huellas de las Mujeres en Basauri, Basauri, Ayuntamiento de Basauri.

FERNÁNDEZ, Z. (2012): Emakumeen eta mugimendu feministaren oroimena Ondarroan, Euren Aztarnaren Bitartez, Ondarroa, Ondarroako Udala.

FERNÁNDEZ, Z. (2014): Aztarna feministak eta Emakumeen aztarnak: gure borrokaren oroimena. Huellas feministas y de mujeres: Memoria de nuestra lucha, Ermua, Ayuntamiento de la Villa de Ermua.
FERNÁNDEZ, Z. (2015): “Cartografía de la memoria colectiva de las mujeres en los municipios vascos: el mapa de las huellas educativas de las mujeres y del feminismo", en K. BUJAN, K. MACEIRA, L. REKALDE, I. ORBEGOZO, I. GORESPE, B. ARIZTIZABAL, P. y BILBAO, B.: Educación, memoria e historia de las mujeres vascas, lecturas feministas, pp. 217-243. País Vasco, Intxorta 1937 Kultur Elkartea.

LARRAÑAGA, C. (2007): Del bertsolarismo silenciado, Donosti, Miramar Jauregia.

LÓPEZ, O. (2011): La defensa del derecho al propio cuerpo y la construcción del Movimiento Feminista. Juicios por aborto a 11 mujeres de Basauri, 1976-1985, tesina, <http:// www.pensamientopenal.com.ar/system/ files/2014/12/doctrina35871.pdf 〉.

MARTíN, A. (2007): Red de Escuelas de Empoderamiento para Mujeres. Acercamiento experiencias de Educación para el desarrollo. Entrevista con Círculo Solidario, Bilbao, Círculo Solidario Euskadi, Euskadiko Elkarbidea.

PÉREZ, J.A. (2006): “La construcción y transmisión de la identidad política antifranquista. Una aproximación desde la historia oral de las mujeres de Basauri", Vasconia, 35, pp. 387405.

SEN, A. (2000): Desarrollo y libertad, Barcelona, Editorial Planeta.

VÁZQUEZ, N. (2009): “Promoción del empoderamiento de las mujeres desde la práctica”, en MOYUA, I.: Empoderamiento y participación sociopolítica de las mujeres. Jornada de preparación del Foro por la Igualdad, Vitoria-Gasteiz, Emakunde.

URZELAI, R.M. (2014): El empoderamiento de las mujeres. La ruta para una vida equitativa y segura, tesis de pregrado, <http://repositori.uji.es/xmlui/ bitstream/handle/10234/107662/TFM_2013 urzelai R.pdf; jsessionid $=46 \mathrm{C}_{9} \mathrm{E} 2 \mathrm{EDBFB} 12 \mathrm{CC}_{22}$ 431B9C95A803b4D? sequence $=1$.

ZABALA, B. (2008): Movimiento de Mujeres, Mujeres en Movimiento, Nafarroa, Txalaparta. 